\title{
Alcohol consumption amongst young adults living in a low socioeconomic status community in Cape Town
}

\author{
Sabirah Adams, Shazly Savahl, Serena Isaacs and Cassandra Zeta Carels
}

\begin{abstract}
Our aim was to ascertain the extent of risky alcohol consumption amongst young adults living in a low socioeconomic status community in Cape Town, South Africa. We used a cross-sectional survey design and the street intercept method to administer the Alcohol Use Disorders Identification Test (AUDIT). A key finding in this study was that $54.30 \%$ of male and $47.90 \%$ of the female participants were alcohol dependent, according to the classification criteria set out in the AUDIT. Our finding necessitates further investigations into alcohol consumption amongst young adults in South Africa. In addition, researchers should endeavor not only to identify, but also to understand, the dynamics of risk and resilience factors so that this information could be used to develop intervention initiatives that could mediate young adults' initial consumption of alcohol.
\end{abstract}

Globally, alcohol consumption is recognized as the third leading risk factor for poor health (World Health Organization [WHO], 2010). Approximately 4\% of all deaths worldwide are caused by alcohol, exceeding the number of deaths attributed to human immunodeficiency virus/acquired immunodeficiency syndrome (HIV/AIDS), violence, or tuberculosis (WHO, 2011). The adverse effects of alcohol consumption cause an estimated 2.5 million deaths every year, of which a significant proportion occur amongst young people (WHO, 2010).

South Africa, in particular, has been shown to have one of the highest alcohol consumption rates per capita in the world (Parry, 2005; WHO, 2011). According to the WHO in a report prepared in 2011, South Africa received a score of 4 out of 5 on a scale to measure risky patterns of drinking alcohol, with South African males reporting consuming five or more alcoholic drinks in one sitting, and women consuming more than three alcoholic drinks in one sitting. In the Western Cape Province of South Africa, alcohol has been identified as one of the primary substances of abuse (South African Community Epidemiology Network on Drug Use, 2010). In the most recent South African Demographic and Health Survey (SADHS, 2007) it was reported that in the Western Cape province, $70.3 \%$ of males indicated that they had ever consumed alcohol, $55.1 \%$ indicated that they consumed alcohol in the past 12 months, and $37.3 \%$ having consumed alcohol in the past 7 days. Furthermore, $39.2 \%$ of females indicated that they had ever consumed alcohol, 28.8\% indicated that they consumed alcohol in the past 12 
months, and $\mathbf{1 8 . 8 \%}$ indicated that they consumed alcohol in the past 7 days. The most recent available statistics indicate lifetime alcohol use in the Western Cape to be 30.60\%, and daily use to be $\mathbf{1 7 . 8 0 \%}$ (Harker et al., 2008). Moreover, results from a number of household surveys have indicated that the lifetime prevalence of alcohol use ranged from $39 \%$ to $69 \%$ in the Western Cape, with the prevalence of risky drinking or problematic use of alcohol among drinkers ranging from $9 \%$ to 34\% (Shisana et al., 2005). Although the etiology of alcohol abuse in South Africa and the Western Cape is multifactorial, there is acknowledgement that it is rooted in the sociopolitical history of the country (see e.g., Chopra \& Sanders, 2004; Pithey \& Morojele, 2002). Decades of institutionalized racism, systematic oppression, and the resulting context of social inequality and impoverishment have been identified as the driving factors behind the high rates of alcohol consumption. These conditions in South African society, along with a number of nefarious labor practices, whereby workers were remunerated with alcohol, have resulted in a culture of alcohol abuse (Ruddock, 2012).

Consistent with a number of international studies in which researchers have found higher rates of lifetime alcohol use for males than females (WHO, 2010), trends in the Western Cape have been shown to be similar (Harker et al., 2008; South African Community Epidemiology Network on Drug Use, 2010). Hazardous drinking of alcohol, assessed using the Alcohol Use Disorder Identification Test (AUDIT) amongst a sample of young South Africans aged between 15 and 24 years, revealed that $10 \%$ of men and 2\% of women were classified as hazardous drinkers (South African National HIV Prevalence, Behaviour and Communication Survey, 2005). However, this disparity in level of alcohol consumption between males and females has been observed to decrease in recent years, with male and female alcohol use becoming more similar (Reddy et al., 2003). In other studies it has been suggested that females have higher rates of binge drinking than their male counterparts (WHO, 2010).

Alcohol use among adolescents and young adults is associated with a multitude of risk behaviors and consequences, including lowered inhibitions resulting in risky sexual behavior and the transmission of HIV, use of illegal substances, violence, driving under the influence of alcohol, alcohol-related traffic injuries or fatalities (Peltzer \& Ramlagan, 2009), suicide (Ramsoomar \& Morojele, 2012), and fetal alcohol spectrum disorders (Peltzer \& Ramlagan, 2009). In previous studies researchers have focused primarily on adolescents in formal educational settings (Flisher, Ziervogal, Charlton, Leger, \& Robertson, 1996, 1997, as cited in Pithey \& Morojele, 2002) and clinic-based populations receiving treatment for sexually transmitted infections (STIs) (Kalichman, Simbayi, Cain, \& Jooste, 2007). However, although statistics suggest that those in the age group between 18 and 25 years are the most likely to abuse alcohol (Ramsoomar \& Morojele, 2012), there is a paucity of research concerning this age cohort.

Considering the above, in this study our aim was to ascertain the extent of risky alcohol consumption amongst young adults in a low socioeconomic status community in the Cape Flats area of Cape Town, South Africa. 


\section{Method \\ Design}

We used a cross-sectional survey design to collect data from a sample of young adults between the ages of 18 and 25 years. Visser, Krosnick, and Lavrakas (2000) state that this is a valid and reliable design method to employ to document the prevalence of a specific characteristic within a subset of the population at one point in time.

\section{Research Context}

We conducted the survey on the Cape Flats in the Western Cape, South Africa, with a population size of approximately 19,169 (Okecha, 2011), in a community characterized by high levels of poverty, unemployment, crime, substance abuse, poor infrastructure, and low levels of education (Savahl, 2010), situated approximately $15 \mathrm{~km}$ from the Cape Town central business district. The Cape Flats is an extensive area of flat land located on the periphery of Cape Town encompassing a number of "Coloured" 1 and "Black" townships (Savahl, 2010). These terms were employed as derogatory racial categories within the Apartheid era to reinforce institutionalized oppression of the majority of the population and refer to those who were systematically discriminated against, denied access to resources, and not afforded the same benefits as "Whites" in this era.

\section{Sampling}

The sample consisted of 70 male and 73 female participants $(N=143)$, between the ages of 18 and 25 years. The literature has identified this age cohort as most at risk for alcohol use in South Africa (South African Community Epidemiology Network on Drug Use, 2010). To access participants, we used the street intercept method, a nonprobability sampling technique whereby people are approached on the street and asked if they are prepared to allocate a few minutes to complete an anonymous questionnaire (Simbayi et al., 2006). The street intercept method was advantageous as it allowed us to expeditiously recruit from the general public participants who met the inclusion criteria of age and area of residence. This method has previously been used effectively in establishing patterns of use of alcohol (Spooner \& Flaherty, 1993) and crystal methamphetamine (Simbayi et al., 2006).

\section{Instruments}

The data-gathering instrument we used was the Alcohol Use Disorder Identification Test (AUDIT) (Saunders, Aasland, Babor, De La Fuente, \& Grant, 1993). The AUDIT is a self-administered questionnaire that was developed to identify persons whose alcohol consumption has become hazardous to their health. The items are scored using a $5^{-}$ point Likert scale and the questionnaire takes approximately two minutes to complete. Sample items are "How often do you drink alcohol?", with response options never, once a month, 2-4 times a month, 2-3 times a week, and 4 or more times a week, and the item "How often during the last year did you need a drink in the morning to feel better after heavy drinking the night before?", with response options never, less than once a

\footnotetext{
${ }^{1}$ The terms 'Coloured', 'Black', and 'White' are used here solely for descriptive purposes, and do not imply acknowledgement of these terms as valid by the authors. During Apartheid, under the Population Registration Act No. 30 of 1950, three main racial categories were delineated. 'White' referred to those of European descent; 'Black' referred to black native Africans; and 'Coloured' referred to people of mixed descent (Population Registration Act, 1950). The 'Coloured' group included people of Khoisan, Malaysian, Griqua, Indian, and Chinese origin (as cited in SADHS, 2007).
} 
month, monthly, weekly, and daily or almost daily. The cut-off scores for the AUDIT are as follows: a score of 8 or more is associated with harmful or hazardous drinking, and a score of 13 or more in women, and 15 or more in men, indicates alcohol dependence (Babor, Higgins-Biddle, Saunders, \& Monteiro, 2001). Reliability studies on the AUDIT using measures of test-retest and internal consistency have indicated high internal consistencies ranging from 0.83 (Reinert \& Allen, 2007; Swanholm, Vosvick, \& Chng, 2009) to 0.98 (Leung \& Arthur, 2000), suggesting that the AUDIT is measuring a single construct. A test-retest reliability study indicated high reliability $(r=0.86)$ in a sample consisting of nonhazardous drinkers, cocaine users, and alcohol abusers.

Within Cape Town there are three official languages: namely, English, Afrikaans, and Xhosa. However, within the community under investigation, Afrikaans and English are the languages that are predominantly spoken (Statistics South Africa, 2011). The questionnaire, which was in English in its original form, was, therefore, translated into Afrikaans using the back-translation method. Participants were given the option to answer the questionnaire in either English or Afrikaans.

\section{Procedure and Ethics}

Ethical clearance was obtained from the University of the Western Cape, and the Western Cape Education Department. Prospective participants were approached on the street and were fully informed of the purpose of the study, their intended role in it, and that they could withdraw from the study at any time without prejudice. Participants were further assured of the anonymity of their participation. Written informed consent was obtained from the participants prior to their completing the questionnaire. We ensured that no harm of any kind was brought upon the participants. We made counseling support available to the participants, if required. The data were captured, cleaned, and verified by the research team, and the completed questionnaires were then destroyed. The data were analyzed using the Windows-based version of the IBM Statistical Package for the Social Sciences (SPSS) 20.

\section{Results}

Table 1. Level of Alcohol Consumption of Males and Females

\begin{tabular}{lcccc}
\hline & \multicolumn{2}{c}{ Males } & \multicolumn{2}{c}{ Females } \\
& $F$ & $\%$ & $F$ & $\%$ \\
\hline No dependence & 18 & 25.7 & 25 & 34.2 \\
Harmful drinking & 14 & 20 & 13 & 17.8 \\
Alcohol dependent & 38 & 54.3 & 35 & 47.9 \\
\hline
\end{tabular}

The results indicate that $20 \%$ of males and $17.80 \%$ of females were harmful or hazardous drinkers. The results further indicate that $54.30 \%$ of the males and $47.90 \%$ of the females were alcohol dependent.

A means analysis was conducted and revealed that, for both males $(M=15.33 ; S D=$ 10.14) and females $(M=13.33 ; S D=10.43)$, the mean score was higher than the AUDIT's cut-off score for alcohol dependence, that is, a score of more than 13 for 
females and more than 15 for males. An independent samples $t$ test showed no significant difference in alcohol dependence between males and females $(t=1.27 ; p>$ $.05 ; d f=141)$.

\section{Discussion}

Our aim in this study was to ascertain the extent of risky alcohol consumption amongst young adults in a low socioeconomic status community in Cape Town, South Africa. A key finding in this study was that $54.30 \%$ of males and $47.90 \%$ of the female participants were classified as alcohol dependent according to the classification criteria set out in the AUDIT. According to findings in previous research (Bradshaw \& Steyn, 2002) these statistics are a typical portrayal of alcohol consumption in communities characterized by poverty. Additionally, these results are concerning because the harmful use of alcohol impacts negatively not only upon the individual, but also on the community and the country as a whole (WHO, 2012). In the community under investigation there is an array of socioeconomic, biological, and cultural factors that propagate the consumption and hazardous use of alcohol. These factors include gender, socioeconomic status, genetic predisposition, physical health status and medical conditions, social norms, beliefs, and expectations that are pivotal in determining the risks with which an individual is confronted (see e.g., Adams et al., 2013; Arias, Feinn, \& Kranzler, 2005; Dick \& Agrawal, 2008; Mattern \& Neighbors, 2004; Morojele et al., 2004, 2006; Wang et al., 2007).

The socioeconomic environment of the Cape Flats community, which is a legacy of the political history of South Africa, characterized by poverty, unemployment, crime, violence, and gangsterism, exacerbates the probability of youth and young adults engaging in hazardous drinking, becoming alcohol dependent, and is associated with engaging in risky sexual behavior (Adams et al., in press; Morojele et al., 2004; Parry, 2005; Pitso, 2004). Entrenched in distinctive features of the country's sociopolitical upheaval attributable to its colonial history and the policy of Apartheid, alcohol abuse persists as one of the most pervasive health problems in South Africa. The protracted effects of the dispossession and impoverishment of the majority "Black" population has undoubtedly contributed to many of South Africa's major current social, health, and economic problems, resulting in the destruction of family life, alcohol abuse, one of the highest HIV transmission rates in the world, and various forms of violence. As identified by the WHO (2011, p. 10), lower socioeconomic status and educational levels result in a greater risk of alcohol-related death, disease, and injury, with alcohol abuse being "a social determinant that is greater for men than women". However, in the current study we found that the difference between males and females in terms of the extent of alcohol consumption was not significant. This finding corroborates the findings in another South African study (Reddy et al., 2003), in which a decrease in the disparity in alcohol consumption was identified between males and females in the years immediately preceding the date of the study, despite previous studies in which male alcohol consumption had been recorded as surpassing that of females.

\section{Conclusion}

Epidemiological findings on adolescent and young adult alcohol consumption exhibit a number of disturbing trends that have been substantiated by the key finding in the 
current study. This is, however, not unexpected considering the findings in previous research on youth and young adults in South Africa. Our finding in this study necessitates further investigations into alcohol consumption amongst young adults in South Africa. More importantly, in these studies researchers should endeavor not only to identify, but also to understand, the dynamics of risk and resilience factors that could be used to develop intervention initiatives to address adolescents and young adults' initial consumption of alcohol in low-income and adverse circumstances. A key recommendation would, thus, be for interventions to be implemented which are focus on providing life choice and decision-making skills for adolescents and young adults both in the Cape Flats community and wider population to challenge normalized alcohol consumption, and to advance self-responsibility and socially responsible behaviors by challenging normalized alcohol abuse in the community. Collaboration between policy makers, government departments, lobbyists, community groups, and nongovernmental organizations is necessary to reduce alcohol use and binge-drinking tendencies amongst young adults, with the aim of diminishing alcohol-related harm.

\section{Limitations}

In conducting our study we faced certain limitations shared with other cross- sectional studies. Because of the self-report nature of the instrument we used, the participants' responses were subject to the confines of self-report bias. An additional limitation was that the sample was purposively selected, and drawn from one community only, which may limit the generalizability of the results. 


\section{References}

Adams, S., Carels, C., Savahl, S., Isaacs, S., Brown, Q., Malinga, M., ... Zozulya, M. (in press). Alcohol consumption and risky sexual behaviour amongst young adults in a low-income community in Cape Town. Journal of Substance Use.

Arias, A., Feinn, R., \& Kranzler, H. R. (2006). Association of an Asn40Asp (A118G) polymorphism in the $\mu$-opioid receptor gene with substance dependence: A metaanalysis. Drug and Alcohol Dependence, 83, 262-268. http://doi.org/cdh4rr

Babor, T. F., Higgins-Biddle, J. C., Saunders, J. B., \& Monteiro, M. G. (2001). The Alcohol Use Disorders Identification Test: Guidelines for use in primary care (2nd ed.). Geneva, Switzerland: World Health Organization.

Bradshaw, D., \& Steyn, K. (Eds.) (2002). Poverty and chronic diseases in South Africa: Technical report 2001. Parow, South Africa: Medical Research Council.

Chopra, M., \& Sanders, D. (2004). From Apartheid to globalisation: Health and social change in South Africa. Hygiea Internationalis, 4, 153-174.

Department of Health, Medical Research Council. (2007). South African Demographic and Health Survey. South Africa: Author.

Dick, D. M., \& Agrawal, A. (2008). The genetics of alcohol and other drug dependence. Alcohol Research and Health, 31, 111-118.

Harker, N., Kader, R., Myers, B., Fakier, N., Parry, C., Flisher, A. J., ... Davids, A. (2008). Substance abuse trends in the Western Cape: A review of studies conducted since 200o. Cape Town, South Africa: Department of Social Development.

Kalichman, S. C., Simbayi, L. C., Cain, D., \& Jooste, S. (2007). Alcohol expectancies and risky drinking among men and women at high risk for HIV infection in Cape Town, South Africa. Addictive Behaviours, 32, 2304-2310. http://doi.org/dz6ndz

Leung, S. F., \& Arthur, D. (2000). The Alcohol Use Disorders Identification Test (AUDIT): Validation of an instrument for enhancing nursing practice in Hong Kong. International Journal of Nursing Studies, 37, 57-64. http://doi.org/dwsdkm

Mattern, J. L., \& Neighbors, C. (2004). Social norms campaigns: Examining the relationship between changes in perceived norms and changes in drinking levels. Journal of Studies on Alcohol, 65, 489-493.

Morojele, N., Kachieng'a, M., Mokoko, E., Nkoko, M., Moshia, K., Parry, C., ... Saxena, S. (2004). The relationships between alcohol use and risky sexual behaviour among adults in urban areas in Gauteng Province, South Africa. Parow, South Africa: Medical Research Council.

Okecha, K. (2011). Regime politics and service delivery in the Cape Town Unicity Council area. Urban Forum, 22, 95-110. http://doi.org/cjg3jf

Parry, C. (2005). South Africa: Alcohol today. Addiction, 10o, 426-429. http://doi.org/ckg35n

Peltzer, K., \& Ramlagan, S. (2009). Alcohol use trends in South Africa. Journal of Social Sciences, 18, 1-12.

Pithey, A. L., \& Morojele, N. K. (2002). Literature review on alcohol use and sexual risk behaviour in South Africa. Report prepared for World Health Organization project - Alcohol and HIV infection.

Pitso, J. (2004). Does alcohol use take away condom use? Qualitative evidence from Selibe Phikwe and Mahalapye town districts, Botswana. African Journal of Drug and Alcohol Studies, 3, 53-73. 
Population Registration Act. (1950). Act No. 30. Republic of South Africa, Government Gazette.

Ramsoomar, L., \& Morojele, N. K. (2012). Trends in alcohol prevalence, age of initiation and association with alcohol-related harm among South African youth: Implications for policy. South African Medical Journal, 102, 609-612.

Reddy, S., Panday, S., Swart, D., Jinabhai, C., Amosun, S., James, S., \& Van den Borne, H. (2003). Umthenthe Uhlaba Usamila - The South African Youth Risk Behaviour Survey 2002. Cape Town, South Africa: South African Medical Research Council.

Reinert, D. F., \& Allen, J. P. (2007). The Alcohol Use Disorders Identification Test: An update of research findings. Alcoholism: Clinical and Experimental Research, 31, 185-199. http://doi.org/c55k7w

Ruddock, F. (2012). Capacity building for farm workers on Solms-Delta Wine Estate: A social development perspective. Unpublished master's thesis, University of Stellenbosch, Stellenbosch, South Africa.

Saunders, J., Aasland, O., Babor, T., De La Fuente, J., \& Grant, M. (1993). Development of the Alcohol Use Disorders Identification Test (AUDIT): WHO collaborative project on early detection of persons with harmful alcohol consumption - II. Addiction, 88, 791-804. http://doi.org/fqnr3p

Savahl, S. (2010). Ideological constructions of childhood. Unpublished doctoral dissertation, University of the Western Cape, Bellville, South Africa.

Shisana, O., Rehle, T., Simbayi, L. C., Parker, W., Zuma, K., Bhana, A., ... Pillay, V. (2005). South African national HIV prevalence, HIV incidence, behaviour and communication survey, 2005. Cape Town, South Africa: HSRC Press.

Simbayi, L. C., Kalichman, S. C., Cain, D., Cherry, C., Henda, N., \& Cloete, A. (2006). Methamphetamine use and sexual risks for HIV infection in Cape Town, South Africa. Journal of Substance Use, 11, 291-300. http://doi.org/c7q7kc

South African Community Epidemiology Network on Drug Use. (2010). Monitoring alcohol and drug abuse treatment admissions in South Africa. Retrieved from www.hsrc.ac.za/Research__Publication-22033.phtml

South African National HIV Prevalence, Behaviour and Communication Survey (SABSSM II). (2005). Cape Town, South Africa: HSRC Press.

Spooner, C., \& Flaherty, B. (1993). Comparison of three data collection methodologies for the study of young illicit drug users. Australian Journal of Public Health, 17, 195-202. http://doi.org/ cxm4rw

Statistics South Africa. (2011). Census 2011. Pretoria, South Africa: Author.

Swanholm, E., Vosvick, M., \& Chng, C.-L. (2009). Pessimism, trauma, risky sex: Covariates of depression in college students. American Journal of Health Behaviour, 33, 309-318. http://doi. org/kz5

Visser, P., Krosnick, J., \& Lavrakas, P. (2000). Survey research. In H. Reis \& C. Judd (Eds.), Handbook of research methods in social and personality psychology (pp. 223-252). Cambridge, UK: Cambridge University Press.

World Health Organization [WHO]. (2010). Global strategy to reduce the harmful use of alcohol. Retrieved from www.who.int/entity/mediacentre/factsheets/ts349/en/-3ok

World Health Organization [WHO]. (2011). Global status report on alcohol and health. Geneva, Switzerland: World Health Organization Publications. 
World Health Organization [WHO]. (2012). Global status report on alcohol and health. Geneva, Switzerland: World Health Organization. 